\title{
Isolation of a Mycobacteriophage against Mycobacterium smegmatis
}

\author{
Raquel M. M. Pereira, Hugo V. C. Oliveira, Suanni L. Andrade, \\ Elliot W. Kitajima, and Rudi E. L. Procópio
}

\section{ABSTRACT}

The Mycobacterium genus has important pathogenic species, such as $M$. leprae and $M$. tuberculosis, with high incidence in the human population. The number of bacterial strains resistant to antibiotics is steadily increasing, and in particular no new antibiotics have been developed for Mycobacterium. Mycobacteriophages have been shown to be viable alternatives, mainly to counteract antibiotic-resistant bacteria. A new mycobacteriophage (Myms-1) was isolated from sewage in Manaus, Amazonas state, Brazil, with lytic activity against $M$. smegmatis. Morphological analysis of the Mysm-1 phage shows that it probably belongs to the genus Fromanvirus (family Siphoviridae). It has an icosahedral head with approximate diameter of $50 \mathrm{~nm}$ and a long non-contractile tail with approximate length of $200 \mathrm{~nm}$. $M$. smegmatis is a fast-growing mycobacterium found in the environment that is normally non-pathogenic, so it is a promising bacterium for initial tests of this genus.

Keywords: Mycobacterium, mycobacteriophage, resistance, Shiphoviridae.

Published Online: February 10, 2021

ISSN: 2684-5199

DOI:10.24018/ejbio.2021.2.1.147

R. M. M. Pereira

Amazon State University, Manaus, AM, Brazil.

(e-mail: rmdmp.med@uea.edu.br)

H. V. C. Oliveira

Amazon State University, Manaus, AM, Brazil.

(e-mail: hvoliveira@uea.edu.br)

S. L. Andrade

Amazon State University, Manaus, AM, Brazil.

(e-mail: slandrade@ ${ }^{\circledR}$ uea.edu.br)

E. W. Kitajima

University of São Paulo, Piracicaba, SP, Brazil.

(e-mail: ewkitaji@usp.br)

R. E. L. Procópio*

Amazon State University, Manaus, AM, Brazil.

(e-mail: rprocopio@uea.edu.br)

*Corresponding Author

\section{INTRODUCTION}

The Mycobacterium genus includes important pathogens of humans and animals, such as $M$. tuberculosis, the etiologic agent of tuberculosis, and $M$. leprae, the causative agent of leprosy. The genus Mycobacterium spp. also includes species such as $M$. africanum, M. bovis, M. cannetti, M. caprae, $M$. microti and $M$. pinnipedi, all of which are also considered pathogenic [1]. With each passing year, antibiotic-resistant strains of $M$. tuberculosis are becoming a more serious public health problem, with an effective vaccine not yet available, and the number of people infected growing [2]. Other species of mycobacteria are found in nature (mainly in soil or water), including facultative pathogenic species [3]. M. smegmatis, for example, is a fast-growing mycobacterium found in the environment that is normally non-pathogenic [4], which makes it the bacterium of choice for initial testing of this genus. Characteristics of $M$. smegmatis, such as rapid growth, ease of cultivation in the laboratory, non-pathogenicity and cell wall structure similar to other mycobacteria [5], make this species an ideal model for innocuous and safe investigations [6].

The control of bacteria using bacteriophages started before the use of antibiotics [7], but the ensuing development of antibiotics discouraged the use of bacteriophages. Now with growing antibiotic resistance, a new phase of research with bacteriophages has emerged [8]. The main advantages of bacteriophages is their specificity for a certain bacterium, replication at the site of infection, no need for re-inoculation, absence of side effects, less development of resistance compared to antibiotics, and most importantly, lower cost of development compared to that of new antibiotics [9]-[10]. Within this context, the present work describes the isolation of a mycobacteriophage capable of infecting M. smegmatis.

\section{MATERIAL AND METHODS}

\section{A. Isolation of Bacteriophage}

The M. smegmatis strain was kindly provided by $\mathrm{PhD}$ Maria Francisca Teixeira of the UFAM. The bacterial strain was cultivated in Tryptone Soya Broth -TSB (Pancreatic digest of casein $17.0 \mathrm{~g} / \mathrm{L}$; enzymatic digest of soya bean $3.0 \mathrm{~g} / \mathrm{L}$; sodium chloride $5.0 \mathrm{~g} / \mathrm{L}$; dipotassium hydrogen phosphate $2.5 \mathrm{~g} / \mathrm{L}$; glucose $2.5 \mathrm{~g} / \mathrm{L} ; \mathrm{pH} 7.2$ - Himedia) at $37^{\circ} \mathrm{C}$ for 48 hours. M. smegmatis was used as a host strain for the isolation of mycobacteriophages from sewage. The sewage sample $(100 \mathrm{ml})$ was collected in the neighborhood of Educandos, Manaus, Amazonas (308'12.4"S 
$60^{\circ} 00^{\prime} 28.4^{\prime \prime} \mathrm{W}$ - Google), and filtered through membranes with pore sizes of $1.0 \mu \mathrm{m}, 0.45 \mu \mathrm{m}$ and $0.22 \mu \mathrm{m}$ (Millipore) respectively, to remove debris and bacteria present in the sample. To enrich the phages, $1 \mathrm{ml}$ of the filtrate was added to TSB broth $(20 \mathrm{ml})$ and mixed with $200 \mu \mathrm{L}$ of the $M$. smegmatis culture (optical density of $600 \mathrm{~nm}$, OD600 $=0.6$ ), and incubated at $37^{\circ} \mathrm{C}$ for 18 hours. Then the culture was centrifuged at $12,000 \mathrm{~g}$ for 10 minutes and the supernatant was collected and filtered $(0.22 \mu \mathrm{m}$ membrane $)$ to remove $M$. smegmatis cells. This supernatant was applied in a Petri dish containing $M$. smegmatis grown in solid tryptone soy agar (TSA) to visualize the clear areas where mycobacteriophages grow [11]. Its ability to smooth $M$. smegmatis was evaluated. These mycobacteriophages were used for visualization by electron microscopy.

\section{B. Transmission Electron Microscopy}

After the multiplication of mycobacteriophages in $M$. smegmatis, they were filtered through a membrane with pore size of $0.22 \mu \mathrm{m}$ and suspended in $1 \mathrm{ml}$ of SM buffer $(50 \mathrm{mM}$ Tris-HCl; 100 mM NaCl; 8.5 mM MgSO4; pH 7.5). A $200 \mu 1$ droplet of the filtrate solution containing Mycobacteriophage particles was placed on a Parafilm ${ }^{\circledR}$ surface. Copper grids (200 mesh) covered with carbon-coated Formvar film, were floated on them, film side in contact with the suspension, for $10 \mathrm{~min}$, washed with droplets of distilled water and floated on $200 \mu \mathrm{l}$ droplet of $1 \%$ aqueous uranyl acetate for $10 \mathrm{~min}$, then removed and excess liquid eliminated with a filter paper [12]. These negatively stained preparations were examined with a JEOL JEM 1011 transmission electron microscope at the Electron Microscopy Laboratory, Department of Phytopathology and Nematology, Luiz de Queiroz Superior School of Agriculture, University of São Paulo, Piracicaba, $\mathrm{SP}$, at $60 \mathrm{KV}$, and images were recorded digitally.

\section{RESULTS}

\section{A. Bacteriophage Isolation}

The amplification of mycobacteriophages in the sample is an important strategy to increase the probability of isolating mycobacteriophages, especially if the host bacterium has low density in the sample. An environment such as sewage, probably subjected to constant selective pressures with antibiotics and disinfectants, may favor some groups of bacteria over others and consequently favor their bacteriophages. It was possible to isolate a lytic bacteriophage from the sewage, causing lysis in $M$. smegmatis, as can be seen in Fig. 1 a. The lysis plates had a varied size, showing strong activity against $M$. smegmatis (Fig. 1 b), being able to infect and lyse the host bacteria.

\section{B. Phage Morphology}

Electron microscopy of negatively stained phages showed that they have icosahedral heads of approximately $50 \mathrm{~nm}$ in diameter and long non-contractile tails with approximate length of $200 \mathrm{~nm}$, (Fig. 2 a, 2 b). Thus, morphologically the phage recovered from $M$. smegmatis seems to be a member of the genus Fromanvirus (Duplodnaviria; Heunggongvirae; Uroviricota; Caudoviricetes; Caudovirales; Siphoviridae) [13].

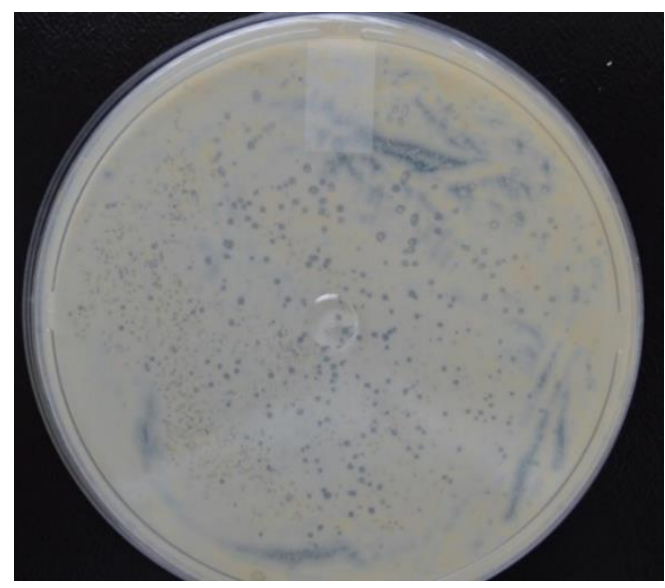

(a)

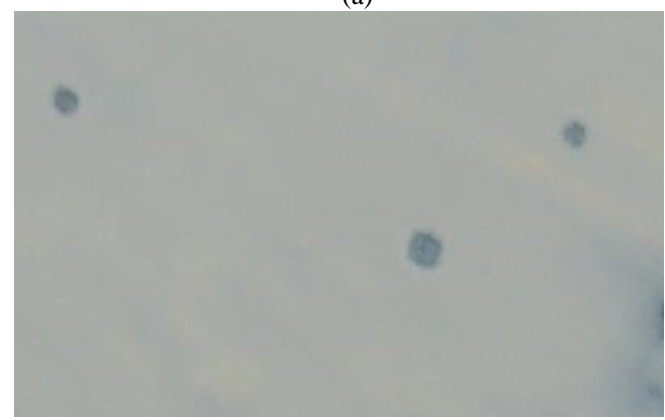

(b)

Fig. 1. Lytic activity of bacteriophages isolated against $M$. smegmatis after enrichment (a). Lysis zones with phages isolated from $M$. smegmatis showing lytic activity (b).

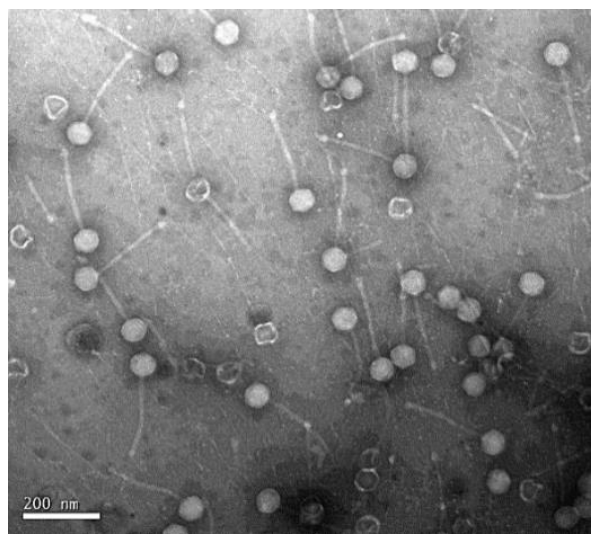

(a)

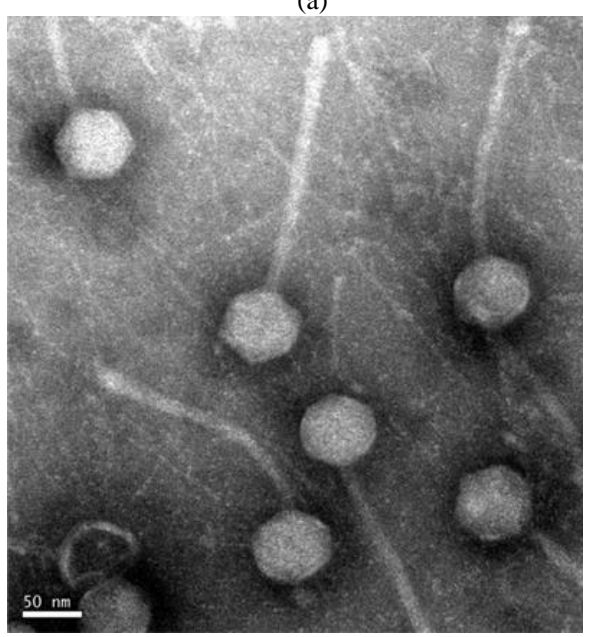

(b)

Fig. 2. Transmission electron micrograph of the mycobacteriophage Mysm1 , showing an uninvolved icosahedral capsid of approximately $50 \mathrm{~nm}$ in diameter, with a $200 \mathrm{~nm}$ flexible contractile tail. A) lower magnification and $\mathrm{B}$ ) higher magnification images. The morphology of the mycobacteriophage Mysm-1 corresponds to that of members of the genus Fromanvirus (family Siphoviridae). 


\section{DisCUSSION}

Several researchers have isolated mycobacteriophages using M. smegmatis [14], with characteristics very similar to the phage Mysm-1 isolated in Manaus, Amazonas. An example is the mycobacteriophage Arlo, a Siphoviridae bacteriophage isolated from soil samples collected in Bluff Dale, Texas [15]. This mycobacteriophage has siphoviral morphology, with a $50 \mathrm{~nm}$ diameter icosahedral nonenveloped capsid and a $125 \mathrm{~nm}$ flexible non-contractile tail. Mysm-1 phage is very similar to Mycobacteriophage L5, which has an icosahedral capsid with diameter of about $60 \mathrm{~nm}$, a flexible tail with length of about $135 \mathrm{~nm}$ and width of $8 \mathrm{~nm}$, with a terminal button and a single short fiber. L5 is classified in the family Siphoviridae and genus Fromanvirus [16]. The vast majority of bacteriophages belong to the order Caudovirales and have a double-stranded DNA genome (dsDNA) enclosed in a polyhedral head, most frequently icosahedral. The tail of the bacteriophage is a structure used during infection to recognize the host and ensure efficient entry from the genome to the cell's cytoplasm. Morphology serves as a basis for the classification of Caudovirales phages [17]. Mycobacteriophages generally fall into two morphological families, the Siphoviridae (with long flexible tails), and the Myoviridae (with contractile tails) [4].

Phage particles are restricted to the host, capable of infecting a narrow spectrum of bacteria, without affecting the host's microbiota, making bacteriophages attractive as tools against antibiotic-resistant bacteria. The phages of mandatory lytic life cycles inject their DNA into the target cell, inducing phage replication and lysis of the bacterial cell wall to release the progeny, thus causing the bacteria to die [18]. The increase in the resistance of $M$ tuberculosis to the antibiotics used has led to new forms of treatment and has aroused interest in the therapeutic use of mycobacteriophages as an alternative to traditional antibiotics. Although bacteriophages have been widely used therapeutically in countries of the former Soviet Union, they have not yet found widespread use in the United States or Europe. Phage preparations have been approved for use against contamination of meat by Escherichia coli and Listeria sp, and tests are underway to control various human infections [14]. Phage therapy has proved to be a viable option in the therapeutic treatment of tuberculosis, an example being phage D29, which significantly decreases the burden of $M$. tuberculosis in the lungs of mice after inhaling aerosol of mycobacteriophage D29 anti-TB [18]. A mycobacteriophage isolated from the soil ( $\phi$ BTCU-1) belonging to the family Siphoviridae with lytic activity against $M$. smegmatis and M. tuberculosis showed excellent activity for both species of bacteria, being stable for one week at $4{ }^{\circ} \mathrm{C}$. After sequencing of its genome, no toxin gene was found in $\phi$ BTCU-1 [19].

Some studies have shown that toxins encoded by phages can contribute to virulence in several bacterial pathogens, including Vibrio cholera, Coynebacterium diphtheria, Salmonella sp. and Escherichia coli. However, there is no evidence of toxins encoded by mycobacteriophages [14]. The vast majority of lytic phages can destroy the host bacterium through the synthesis and assembly of new phages followed by lysis of their host due to the presence of endolysins with antimycobacterial activity [20]. This activity has been observed in mycobacteriophages Mysm-1, active against $M$. smegmatis. Several studies have shown the potential of bacteriophages to control important human pathogens, especially those that have acquired resistance to antibiotics such as Escherichia coli [21] and Enterobacter aerogenes [11], as well as for hard-to-control bacteria such as Staphylococcus aureus [22] and Klebsiella pneumoniae [23]. This makes their clinical application attractive as a new strategy for the control of bacteria [24].

The use of phages has been shown to be an alternative to antibiotics. Phages have high specificity for their hosts, and unlike antibiotics, which have a much broader spectrum, so far they have shown no significant side effects or toxicity risks in human cells. Bacteria are more likely to develop resistance to antibiotics than to phages. In addition, phages have self-replication capacity in the presence of the host and spread widely throughout the body [25].

\section{CONCLUSION}

In this work, we isolated a mycobacteriophage, which we call Mysm-1, which is able to infect $M$. smegmatis due to lysis in the host. The strong lytic activity of these phages against $M$. smegmatis shows that Mysm-1 can be an alternative to antibiotic therapy. In comparison with mycobacteriophages already described, Mysm-1 is similar to those of the family Siphoviridae, and may be included in the genus Fromanvirus.

Further molecular assays are required for a complete characterization of this phage.

\section{ACKNOWLEDGMENT}

The authors thank the financial support from Fundação de Amparo à Pesquisa do Estado do Amazonas (FAPEAM), and Conselho Nacional de Desenvolvimento Científico e Tecnológico (CNPq). To the scientific initiation program of the State University of Amazonas.

\section{REFERENCES}

[1] A. Coros, E. Deconno, K. M. Derbyshire, "IS6110, a Mycobacterium tuberculosis complex-specific insertion sequence, is also present in the genome of Mycobacterium smegmatis, suggestive of lateral gene transfer among Mycobacterial species," Journal of Bacteriology, vol. 190(9), pp. 3408-3410, May 2008.

[2] World Health Organization. 2018. "Global tuberculosis report 2020", World Health Organization, Geneva, Switzerland. https://www.who.int/tb/publications/global_report/en/.

[3] K. Hruska, M. Kaevska, "Mycobacteria in water, soil, plants and air: a review," Veterinarni Medicina, vol. 57(12), pp. 623-679, 2012.

[4] 4 G. F. Hatfull, "Mycobacteriophages," Microbiology spectrum, vol. 6(5) Oct. 2018.

[5] X. Z. Li, L. Zhang, H. Nikaido, "Efflux pump-mediated intrinsic drug resistance in Mycobacterium smegmatis," Antimicrobial Agents Chemotherapy, vol. 48(7), pp. 2415-2423. Jul. 2004.

[6] 6 A. K. Singh J. M. Reyrat, "Laboratory Maintenance of Mycobacterium smegmatis," Current Protocols in Microbiology, vol. 14, pp. 1-10, Aug. 2009.

[7] E. W. Schultz, "The bacteriophage as a therapeutic agent," California and Western Medicine, vol. 31(1), pp. 5-10, Jul. 1929.

[8] S. Reardon, "Phage therapy gets revitalized: The rise of antibiotic resistance rekindles interest in a century-old virus treatment," Nature, vol. 5;510(7503), pp. 15-16. Jun. 2014.

[9] A. Sulakvelidze, Z. Alavidze, J. G. Morris, "Bacteriophage Therapy," Antimicrobial Agents and Chemotherapy, vol. 45(3), pp. 649-659, Mar. 2001.

[10] C. Loc-Carrillo, S. T. Abedon, "Pros and cons of phage therapy Bacteriophage Landes,” Bioscience, vol. 1(2), pp. 111-114, Mar 2011. 
[11] E. Li, X. Wei, Y. Ma, Z. Yin, H. Li, W. Lin, X. Wang, C. Li, Z. Shen, R. Zhao, H. Yang, A. Jiang, W. Yang, J. Yuan, X. Zhao, "Isolation and characterization of a bacteriophage phiEap-2 infecting multidrug resistant Enterobacter aerogenes", Scientific Reports, vol. 20;6:28338 Jun. 2016.

[12] A. C. C. de Melo, A. da Mata Gomes, F. L. Melo, D. M. P. ArdissonAraújo, A. P. C. de Vargas, V. L. Ely, E. W. Kitajima, B. M. Ribeiro, J. L. C. Wolff "Characterization of a bacteriophage with broad host range against strains of Pseudomonas aeruginosa isolated from domestic animals," BMC Microbiology. vol. 17;19(1):134, Jun. 2019.

[13] H. W. Ackermann, "5500 Phages examined in the electron microscope," Archhives of Virology, vol. 152(2), pp. 227-243, Feb. 2007.

[14] G. F. Hatfull, "Mycobacteriophages: windows into tuberculosis". PLoS Pathogens, vol. 20;10(3):e1003953, Mar. 2014.

[15] B. Stewart, M. Adams, M. Fuentes, L. Hanson, E. Sandoval, M. Tovar, C. Trautman, B. Willis, K. Emmert, J. Edwards, J. Meik, J. Pierce, D Edwards, "Complete Genome Sequence of Cluster A1 Mycobacterium smegmatis Bacteriophage Arlo," Microbiology Resource Announcements, vol. 25;7(16):e01242-18. Oct. 2018.

[16] M. K. Donnelly-Wu, W. R. Jacobs Jr, G. F. Hatfull, "Superinfection immunity of mycobacteriophage L5: applications for genetic transformation of mycobacteria," Molecular Microbiology, vol. 7(3), pp. 407-417, Feb. 1993.

[17] D. Veesler, C. Cambillau, "A common evolutionary origin for tailedbacteriophage functional modules and bacterial machineries," Microbiology and Molecular Biology Review, vol. 75(3), pp. 23-33, Sep. 2011.

[18] N. B. Carrigy, S. E. Larsen, V. Reese, T. Pecor, M. Harrison, P. J. Kuehl, G. F. Hatfull, D. Sauvageau, S. L. Baldwin, W. H Finlay, R. N. Coler, R. Vehring, "Prophylaxis of Mycobacterium tuberculosis H37Rv Infection in a Preclinical Mouse Model via Inhalation of Nebulized Bacteriophage D29," Antimicrob Agents Chemother, vol. 16;63(12):e00871-19, Sep. 2019.

[19] C. C. Tseng, D. C. Chang, K. C. Chang, "Development of a Biocontrol Method Applying Bacteriophage-Containing Aerosol against Mycobacterium tuberculosis Using the Bacteriophage BTCU-1 and $M$. smegmatis as Models," Microorganisms, vol. 3;7(8):237, Aug. 2019.

[20] M. J. Lai, C. C. Liu, S. J. Jiang, P. C. Soo, M. H. Tu, J. J. Lee, Y. H. Chen, K. C. Chang, "Antimycobacterial Activities of Endolysins Derived From a Mycobacteriophage, BTCU-1," Molecules, vol. 22;20(10), pp. 19277-19290, Oct. 2015

[21] M. Jamal, T. Hussain, C. Rajanna, S Andleeb, "Isolation and Characterization of a Myoviridae MJ1 Bacteriophage Against MultiDrug Resistant Escherichia coli 3", Jundishapur Journal of Microbiology, vol. 21;8(11):e25917, nov. 2015.

[22] Y. Chang, H. Shin, J. Lee, C. J. Park, S. Y. Paik, S. Ryu, "Isolation and Genome Characterization of the Virulent Staphylococcus aureus Bacteriophage SA97" Viruses, vol. 7(10 ), pp. 5225-5242, Oct 2015.

[23] C. R. Hsu, T. L. Lin, Y. J. Pan, P. F. Hsieh, J. T. Wang, "Isolation of a bacteriophage specific for a new capsular type of Klebsiella pneumoniae and characterization of its polysaccharide depolymerase", PLoS ONE, vol. 2;8(8):e70092 Aug, 2013.

[24] P. Domingo-Calap, P. Georgel, S. Bahram, "Back to the future: bacteriophages as promising therapeutic tools" $H L A$, vol. 87 pp.133140, 2016.

[25] D. Romero-Calle, R. G. Benevides, A. Góes-Neto, C. Billington, "Bacteriophages as Alternatives to Antibiotics in Clinical Care", Antibiotics (Basel), vol. 4;8(3):138. 2019. 